\title{
SiM
}

\section{Rangeland Mashups and Wikicology?}

\section{Implementing Collaborative Internet Technologies for Rangeland Management}

\author{
By Jason W. Karl and Jeffrey E. Herrick
}

\section{On the Ground}

- The same collaborative Internet technologies that fundamentally changed how businesses communicate, create products and services, and ultimately succeed have the potential to contribute greatly to meeting knowledge challenges of rangeland management.

- Web 2.0 tools, like wikis, crowd-sourcing, and content aggregation (i.e., mashups), are currently used in natural resource science and have the potential to increase our understanding of rangeland ecosystems and improve management decision making in the future.

- Taking advantage of this explosion of information will require a change in focus from discrete and isolated projects to comprehensive knowledge systems that can be tapped (and supplemented as necessary) to respond to new management issues as they arise.

Keywords: information systems, knowledge management, metadata, geographic information, online applications.

\section{Rangelands 35(1):11-21}

doi: 10.2111/RANGELANDS-D-12-00069.1

(C) 2013 The Society for Range Management

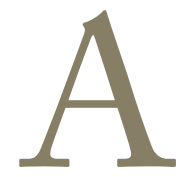

significant challenge facing rangeland management now and in the future is finding and applying relevant knowledge in a changing world. ${ }^{1}$ In their bestselling book Wikinomics, Tapscott and Williams ${ }^{2}$ argue that the rise of collaborative and interactive Web technologies has fundamentally changed how businesses communicate, create products and services, and ultimately compete and succeed. These same technologies have the potential to contribute greatly to meeting knowledge and information challenges of rangeland management. As a profession we need a new paradigm for the creation, discovery, and use of knowledge about rangelands-a kind of rangeland mashup and wikicology that can inform management decision making.

The modus operandi for creating, storing, communicating, and finding information for rangeland ecology and management is based on a centuries-old model of the scientific study - a discrete unit of research that consists of data, analyses, and published results. The traditional unit of information exchanged in this model is a published interpretation of results synthesized from the data collected. Increasingly, uninterpreted data are being made available (e.g., the EcoTrends project), ${ }^{i}$ but the current paradigm limits the ability to address emerging rangeland problems for three reasons. First, the research process is unidirectional-data and information flow from the creators to the consumers. Second, it is insular-studies are planned, data collected, and results reported largely in isolation from the larger community of scientists and managers. Third, the ability to find relevant information is largely limited to thematic searches. To be successful at managing rangeland resources, we need a new paradigm for information and knowledge systems.

Contrast the existing rangeland information and knowledge paradigm with the development of so-called Web 2.0 tools that promote participation, information sharing, interoperability, and collaboration via the Internet. ${ }^{3}$ The advent and widespread adoption of Internet technologies including social networks (e.g., Facebook, LinkedIn, Pinterest), wikis (e.g., Wikipedia), microblogging (e.g., Twitter), crowdsourcing (e.g., OpenStreetMap), content aggregation (i.e., "mashups" like Weather Underground), and mobile devices (e.g., smartphones) has spawned an environment where information consumers can interact directly with producers and contribute directly to creating information. This has fundamentally changed our expectations for being able to find and retrieve useful information and the timeliness of getting it. These changes have in turn led to shifts in the way societies, governments, and businesses operate. ${ }^{2}$

The linkage of these kinds of Web 2.0 technologies to natural resource ecology and management is inevitable. Several aspects of this linkage, however, are unclear: 1) how

'The EcoTrends project can be accessed at http://www.ecotrends.org. 

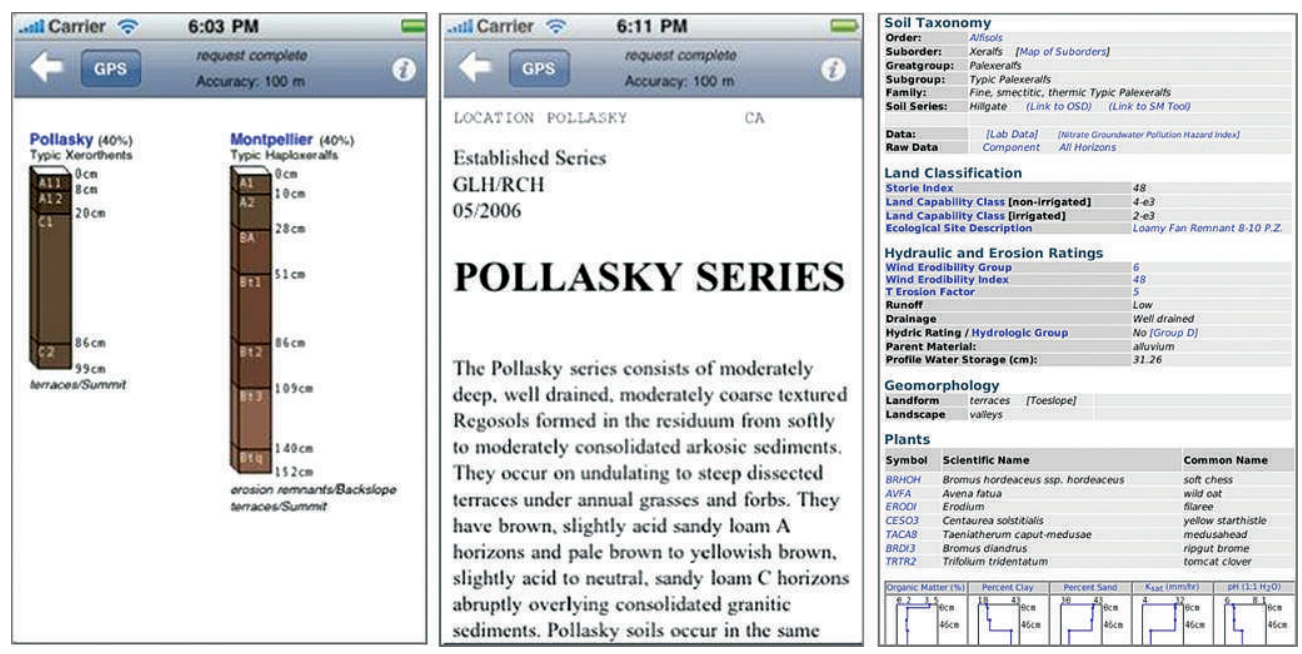

Figure 1. The SoilWeb mobile application developed by the California Soil Resource Lab ${ }^{5}$ gives users instant access to detailed soil survey data from their iPhone or Android mobile device. This application uses the device's global positioning system (GPS) location data to identify the soil map unit and returns the associated soil components. Figure adapted from Beaudette and O'Geen. ${ }^{5}$ Reprinted with permission.

quickly they will be adopted, 2) what benefit will they have to understanding and managing rangeland ecosystems, and 3) whether resulting information and knowledge systems will be developed quickly enough to address emerging land management issues. A study conducted by the Research Information Network ${ }^{4}$ looked at adoption of Web 2.0 technologies for communication and dissemination of information among researchers in various science fields in the United Kingdom. They found that while most of the researchers polled made at least occasional use of Web 2.0 tools in their work, only 13\% used them more than once a week and 39\% did not use them at all. Additionally, most researchers did not consider Web 2.0 technologies to be important to their work because they could not see clear benefits from their use.

In this paper we address three issues. First, we look at how Web 2.0 tools like wikis and crowd-sourcing and new technologies including mobile devices and massive online databases are currently being used in rangeland management. We consider the potential of these tools for further understanding of rangeland ecosystems and improving management decision making. Second, we make recommendations for how effective use of Web 2.0 tools can be improved and integrated in rangeland management. Third, we discuss potential problems and barriers associated with implementing Web 2.0 tools to support a new rangeland knowledge and information management paradigm.

\section{Web 2.0 Tools in Rangeland Management}

There is no single definition for Web 2.0 or a list of technologies that it encompasses, but there are several generally agreed-upon hallmarks: information sharing, interoperability (the exchange of information between unrelated efforts), collaboration, interactive user experiences, using a diversity of interconnected devices, and using the Web as a platform for running applications, not just communicating information. ${ }^{3}$ For the purposes of this paper, a Web 2.0 Web site or tool is one that facilitates the aggregation, sharing, and creation of information and knowledge among a group of users. There are already many Web sites and Web tools relevant to rangeland ecology and management that take advantage of Web 2.0 techniques. Several are highlighted below (see Table 1 for examples).

\section{Access to and Use of Existing Information}

The SoilWeb suite of applications developed by the California Soil Resources Lab ${ }^{\text {ii }}$ demonstrates the potential of Web 2.0 principles to increase access to and use of existing information. SoilWeb provides an easy-to-use interface for the Natural Resource Conservation Service's (NRCS) SSURGO soils data that is an alternative to existing NRCS tools like WebSoilSurvey.iii In addition to simple Internet-browser and Google Earth applications for finding soils information, versions of SoilWeb have been developed for Android and iPhone mobile devices to facilitate easier access to and use of soils information while in the field (Fig. 1). Anecdotal reports indicate that a number of rangeland professionals have purchased these devices specifically because of the availability of SoilWeb. SoilWeb also has an open application programing interface that exposes the underlying data in a manner that other developers can create Web 2.0 applications that request and receive soils data from the SoilWeb servers.

\section{Collaboration and Knowledge Systems}

A defining feature of Web 2.0 is collaboration between groups of people. This represents a switch from using the Internet for one-way information dissemination (i.e., information is created and published by "experts" and made available to a

\footnotetext{
ii The SoilWeb suite of applications can be accessed athttp://casoilresource. lawr.ucdavis.edu/drupal/node/902.

iii The WebSoilSurvey can be accessed at http://websoilsurvey.nrcs.usda.gov.
} 


\begin{tabular}{|c|c|c|c|c|c|c|c|c|c|}
\hline Interactive data analysis tools & & & & & & $x$ & $x$ & & \\
\hline Wiki/user comment/discussion & $x$ & & $x$ & & & & $x$ & + & \\
\hline Social networking & & & & & $x$ & & & & \\
\hline Geographic analysis & & & & & & $\times$ & & & \\
\hline Geographic search & & $\times$ & & & & $\times$ & & $\times$ & \\
\hline Web service & & $\times$ & & $\times$ & & & $\times$ & & \\
\hline Online database & & $\times$ & & $\times$ & & $\times$ & $\times$ & $\times$ & \\
\hline Mobile app & * & $\times$ & & & & & & & \\
\hline Data crowd-sourcing & & & & & & $x$ & & $\times$ & \\
\hline Content aggregation & $\times$ & & * & & & $\times$ & $\times$ & $\times$ & \\
\hline RSS feed & $\times$ & & $\times$ & & $x$ & & $\times$ & $\times$ & \\
\hline Blog & & & & & $\times$ & & & $x$ & \\
\hline Multimedia learning resources & $\times$ & & & & & & $\times$ & & \\
\hline Data mining & $x$ & & & & & & & & \\
\hline 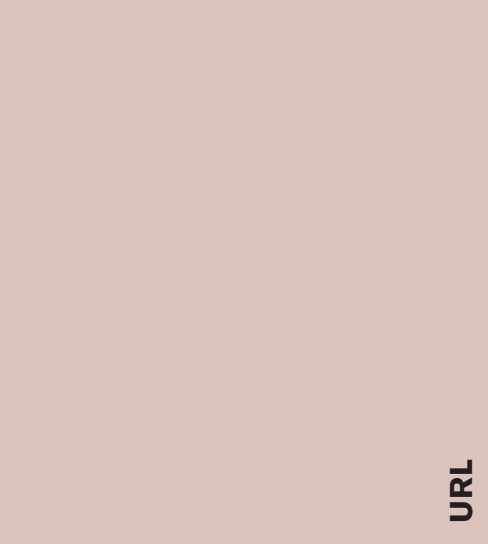 & 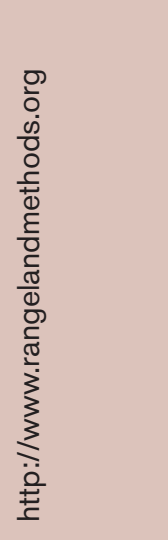 & 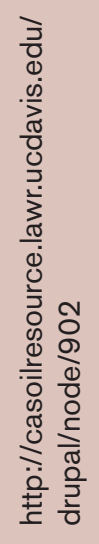 & 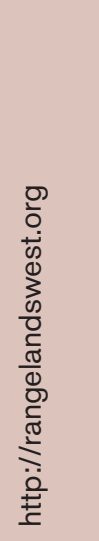 & 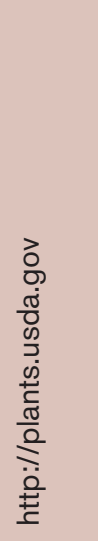 & 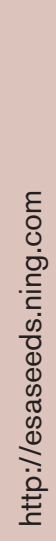 & 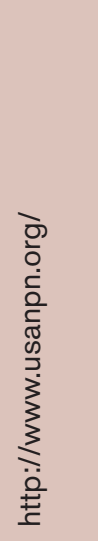 & 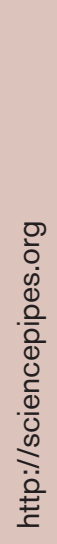 & 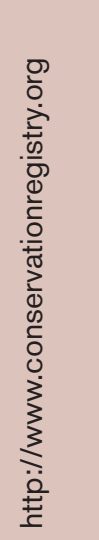 & 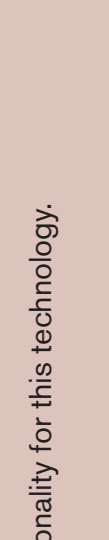 \\
\hline 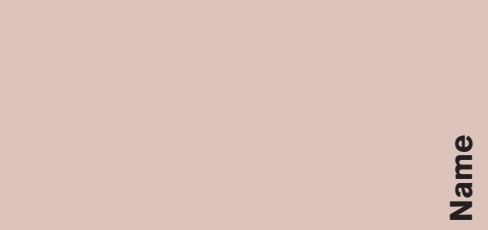 & 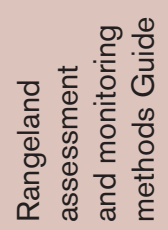 & 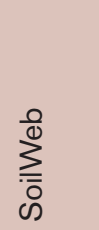 & 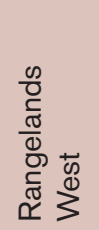 & 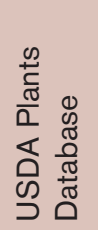 & 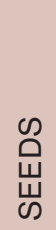 & 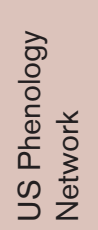 & 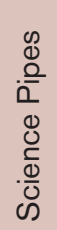 & 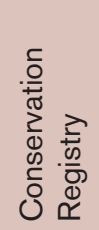 & 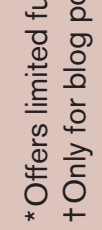 \\
\hline
\end{tabular}




\begin{tabular}{|c|c|c|c|c|c|c|c|c|c|c|}
\hline Interactive data analysis tools & & & & $\times$ & & $\times$ & & & & \\
\hline Wiki/user comment/discussion & & $x$ & & & & & & & & \\
\hline Social networking & & $\times$ & & $\times$ & & & & & & $\times$ \\
\hline Geographic analysis & & & & $\times$ & & $\times$ & & & & \\
\hline Geographic search & $\times$ & & $\times$ & $\times$ & $\times$ & $\times$ & & $\times$ & $x$ & $\times$ \\
\hline Web service & $\times$ & & & & & $x$ & & & & $x$ \\
\hline Online database & $\times$ & & $\times$ & $\times$ & $x$ & $\times$ & $\times$ & $x$ & $x$ & \\
\hline Mobile app & & & & & & $\times$ & & $\times$ & & \\
\hline Data crowd-sourcing & & & $\times$ & $x$ & & $\times$ & & $x$ & & $x$ \\
\hline Content aggregation & & & $\times$ & $\times$ & & & & & $\times$ & $x$ \\
\hline RSS feed & & $\times$ & $\times$ & $\times$ & & $x$ & $\times$ & & & \\
\hline Blog & & $\times$ & $\times$ & $\times$ & & $\times$ & & & & \\
\hline \multicolumn{11}{|l|}{ Multimedia learning resources } \\
\hline Data mining & & & & & & & & & $x$ & \\
\hline$\overline{\underline{\Sigma}}$ & 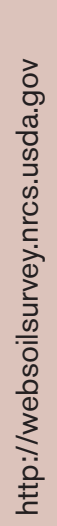 & 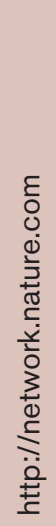 & 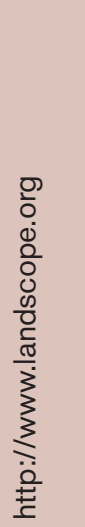 & 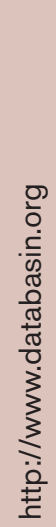 & 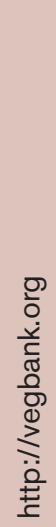 & 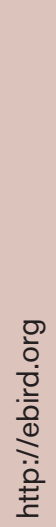 & 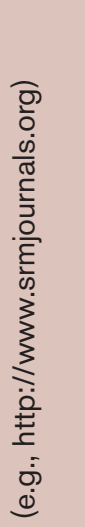 & 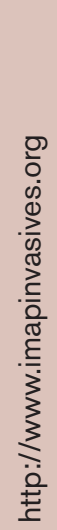 & 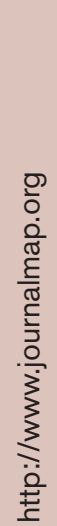 & 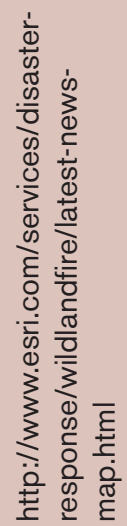 \\
\hline$\stackrel{\stackrel{2}{E}}{\text { Z }}$ & 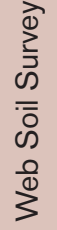 & $\begin{array}{l}\frac{r}{2} \\
\vdots \\
0 \\
2 \\
0 \\
\frac{1}{3} \\
\frac{\pi}{Z}\end{array}$ & 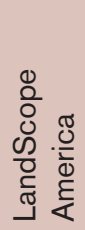 & $\begin{array}{l}\frac{1}{0} \\
\tilde{\sigma} \\
0 \\
\sigma \\
\tilde{\pi} \\
0\end{array}$ & 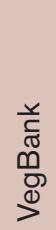 & 旁 & 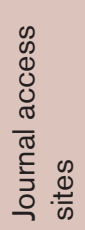 & 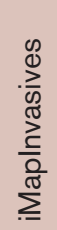 & 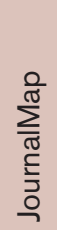 & 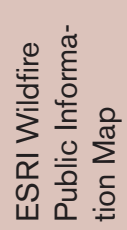 \\
\hline
\end{tabular}




\section{LandscapeToolbox}

Tools and Methods for Effective Rangeland Management

Toolbox Wiki Home Help Register Login SHARE GV凶.

Trace: s Landscape Toolbox Wiki

8. Select Language $\mid \nabla$

\section{Landscape Toolbox Wiki}

Welcome to the main page of the Landscape Toolbox Wiki. These wiki pages contain information on various field and remote sensing methods that can be used in assessing and monitoring rangelands. This is a wiki - contribute your knowledge and experience!! Read our Frequently Asked Questions.

Report a bug, broken link, or incorrect content

- Field Methods - ways for measuring rangeland attributes that require an observer or instrument to be located at the site

\begin{tabular}{|l|}
\hline Table of Contents \\
\hline - Landscape Toolbox Wiki \\
- Tag Cloud \\
= Login/Register \\
- Get Involved! \\
- More Information \\
- Get Help! \\
\hline
\end{tabular}

- Remote Sensing Methods - ways to measure rangeland attributes through the analysis and interpretation of aerial or satellite imagery.

- Remote Sensor Types - Remote sensing methods are usually applicable to more than one source of imagery

- Spatial Analysis Methods - methods for analyzing spatially explicit data including measures of spatial dependency, spatial predictions and point pattern analysis

- Databases - Databases for storage and organization of information or data related to rangelands

Not sure what methods to use?

Check out the

To help you decide

- Protocols - Standardized groups of methods for collecting data to address a specific objective

- Tools - Analytical methods, models or software that create value-added outputs in the form of summaries, estimates, predictions, or syntheses.

- Sample Design - Discussion and tools related to sample design

- Glossary - A comprehensive glossary of rangeland assessment and monitoring terms.

This wiki and the Methods Guide are intended to be a users' first step to selecting assessment and monitoring protocols by providing enough information on strengths, limitations, and rangeland applications that users can seek additional, more specific how-to information on the recommended techniques.

\section{Tag Cloud}

The most frequently used key words

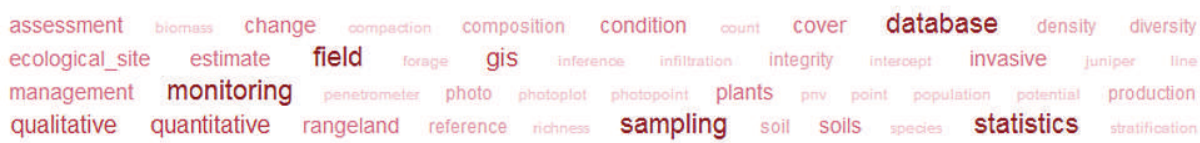

Figure 2. The Rangeland Assessment and Monitoring Methods Guide (http://www.rangelandmethods.org) uses a wiki format for disseminating information on monitoring methods. The wiki makes it easy to engage a large group of people to help create and edit discussions of the merits and limitations of aspects of monitoring data collection and study design.

group of users) to a paradigm where communities of experts and users all contribute their knowledge, experiences, and observations. One Web 2.0 tool that has taken this approach is the Rangeland Assessment and Monitoring Methods Guide (hereafter Methods Guide), an online tool and information resource for helping rangeland professionals decide which data collection methods will best suit their monitoring or assessment needs. ${ }^{6}$ The Methods Guide is built around a wiki ${ }^{\text {iv }}$ (specialized Web site where groups of users can create or edit

iThe Methods Guide wiki can be accessed at http://wiki.landscapetoolbox.org. content on the site) where the details and uses of different field and remote-sensing data-collection methods are discussed (Fig. 2). The wiki allows experts to directly contribute their knowledge about the relative merits, limitations, and applications of methods via the Web site. Nonexpert users can contribute via a comment section on each wiki page. All changes to the Methods Guide wiki are monitored to ensure the quality of the site's information.

\section{Crowd-sourcing}

Crowd-sourcing, where the users directly contribute the data that are contained and served on a Web site, is another 


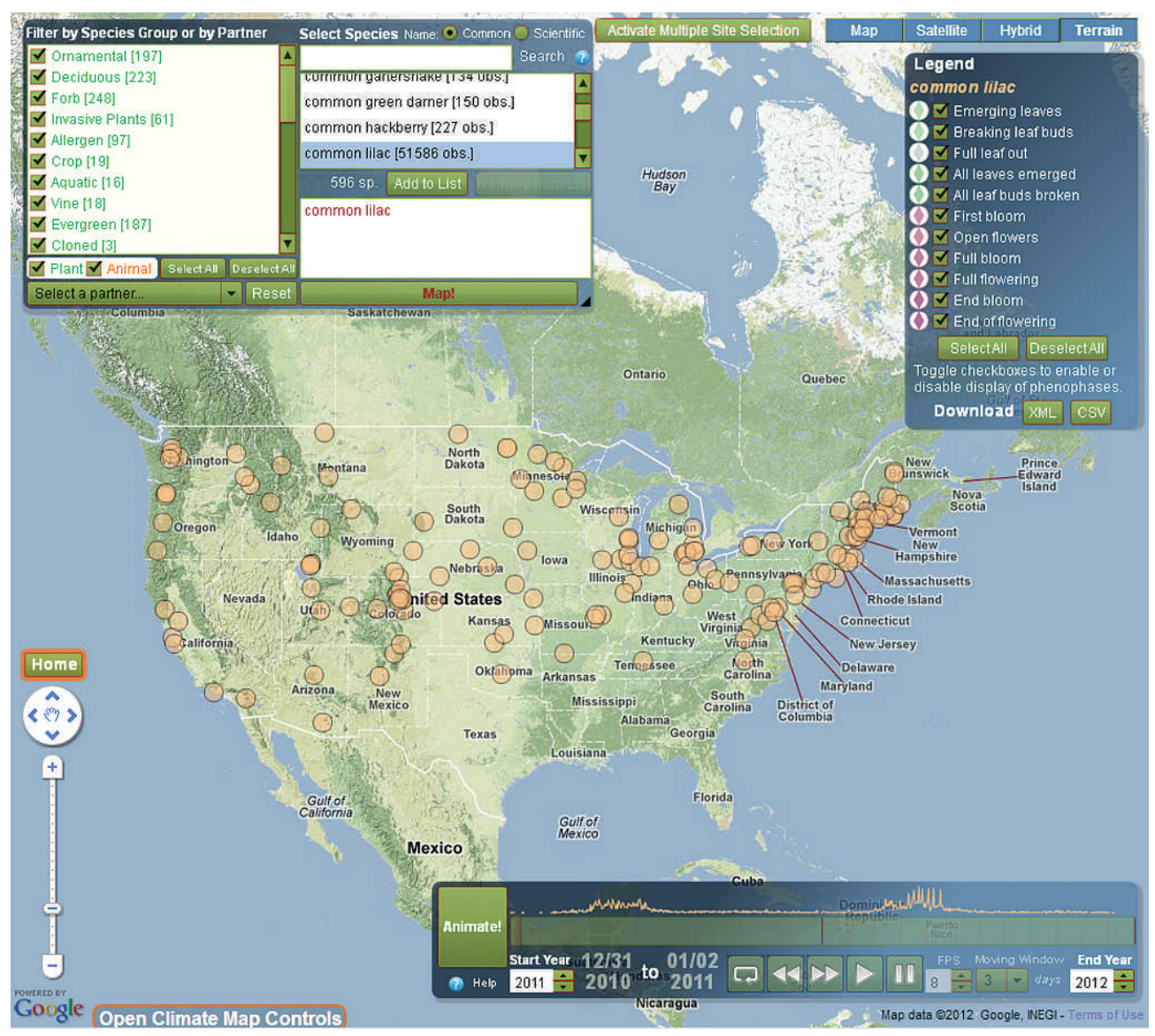

Figure 3. Example of time-series data on common lilac (Syringa vulgaris L.) contributed to the USA National Phenology Network (http://www.usanpn. org) by site users. These data show the timing of plant pheno-phases and how they have changed over time.

emerging Web 2.0 technique. The USA National Phenology Network $^{7}$ is an example of an application that uses crowdsourcing to collect its data. ${ }^{v}$ The goal of the National Phenology Network is to monitor impacts of climate change on plants and animals in the United States. Site users submit observations of plants or animals and their phenophases (e.g., bud break, flowering) or life cycle stages (e.g., migration). Through the contributions of many users, regional and national patterns can emerge. The site provides interactive, map-based tools for exploring, animating, and analyzing the user-contributed data (Fig. 3).

\section{Content Aggregation}

Content aggregation is acquiring and displaying information related to a specific topic from many different sources. Content aggregation is about more than "one-stop-shopping" for information though. By presenting related data from different sources together on one site, understanding can be improved of how systems function and change. What makes Web 2.0 content aggregation different from past efforts in the ecological sciences is that the search and display of the

vThe USA National Phenology Network can be accessed at http://www. usanpn.org. related information happen in real-time when the user requests the information. An example of this is the Wildfire Public Information Map application ${ }^{\text {vi }}$ developed by ESRI (Fig. 4). This Web site pulls together information on wildfires, fire conditions, news, and observations from many different sources, including the National Interagency Fire Commission, the National Weather Service, the National Oceanic and Atmospheric Administration, Twitter, YouTube, Flickr, and local news sources. For individual fires, information on the fire's status, extent, news stories, Twitter feeds, YouTube videos, and photos are presented. The ESRI Wildfire Public Information Map provides one place where almost all information on a given fire can be found.

\section{Potential of Web 2.0 to Contribute to Understanding Rangeland Ecosystems}

As more data sets and information repositories (i.e., journal archives) are made available online and as interoperability between these efforts increases, the potential for these data, facilitated by Web 2.0 technologies, to contribute to our un-

\footnotetext{
viThe Wildfire Public Information Map application can be accessed at http://www.esri.com/services/disaster-response/wildlandfire/latestnews-map.html.
} 


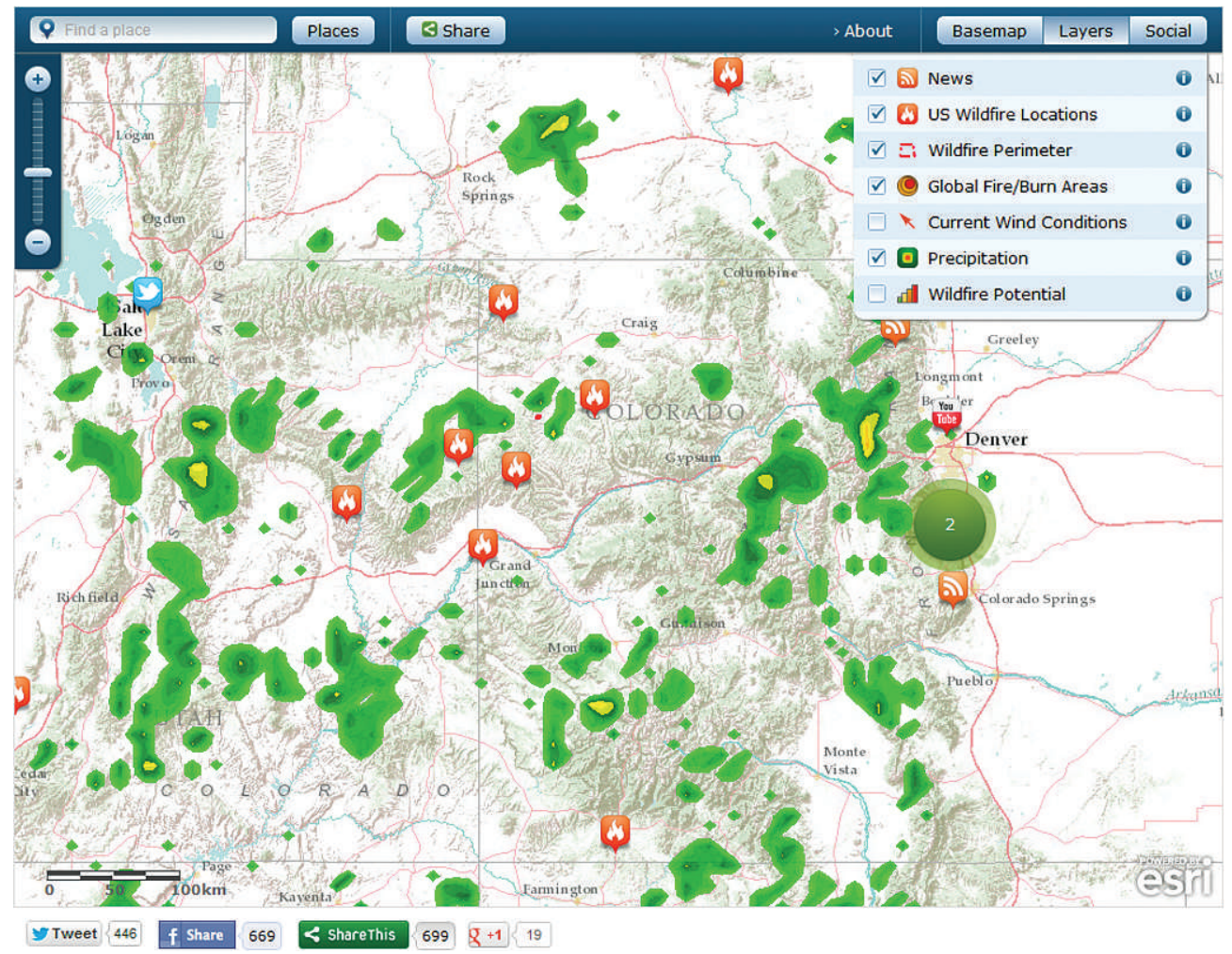

Figure 4. A demonstration of content aggregation for wildfires produced by ESRI (http://www.esri.com/services/disaster-response/wildlandfire/latestnews-map.html). This Web application pulls together information on wildfires from many different sources. For individual fires, current information on the status of the fire from the National Interagency Fire Commission is displayed along with news stories and Twitter feeds. All data presented are accessed automatically at the time the user goes to the site.

derstanding of rangeland ecosystems increases. Two examples illustrate this potential.

\section{Mining Existing Sources for New Information}

Many published ecological studies were conducted in the field, and geographic information describing where these study sites were is included in the published article (although the quality of this information is inconsistent). With most journals now making their archives available online, it is possible to mine the geographic information from these articles. Having the locations of field studies cataloged in online databases opens up the possibility to search for relevant literature by geography as well as by keyword or topic. The JournalMap Web site ${ }^{\text {vii }}$ is an example of this (Fig. 5). Beyond searching for knowledge in a specific area, JournalMap also facilitates identification of potentially relevant knowledge from other parts of the world that are ecologically similar through searches based on soils, climate and vegetation attributes. This could better leverage existing knowledge information to understand the functioning of ecosystems and their response to management and disturbance. Geographic information for published studies has long been included in journal articles, but the use of the Internet as a means of dissemination has now made this information accessible.

\footnotetext{
viiThe JournalMap Web site can be accessed at http://www.journalmap.org.
}

\section{Combining Different Datasets in Novel Ways}

The SciencePipes application, ${ }^{\text {viii }}$ developed by the Cornell Laboratory of Ornithology, represents a new approach to accessing and analyzing data sets that is made possible through Web 2.0 technologies. SciencePipes gives users direct access to three global databases that represent more than 60 million observations (eBird, Project Feeder Watch, and the World Wildlife Fund WildFinder) and tools to combine and analyze those data. Users use a "visual programming interface" to construct workflows that query, compare, analyze, and graph data sets (Fig. 6). Workflows provide documentation of the analysis process and can be saved, shared with other users, or embedded in other Web sites. SciencePipes encourages users to develop new analyses to meet their specific needs and to experiment with combining and looking at data in new ways rather than providing preformatted, static analysis results. This kind of technology has great potential for rangeland ecology and management and can provide a platform for making many existing databases more accessible to the public. By providing access to data through Web services and interactive Web tools like SciencePipes, data managers could maintain control over the scale and types of analyses performed. This would help address concerns over privacy issues

viiiThe SciencePipes application can be accessed at http://sciencepipes. org. 


\section{JournalMap ${ }^{\text {Tw }}$}

Research. Reimagined.

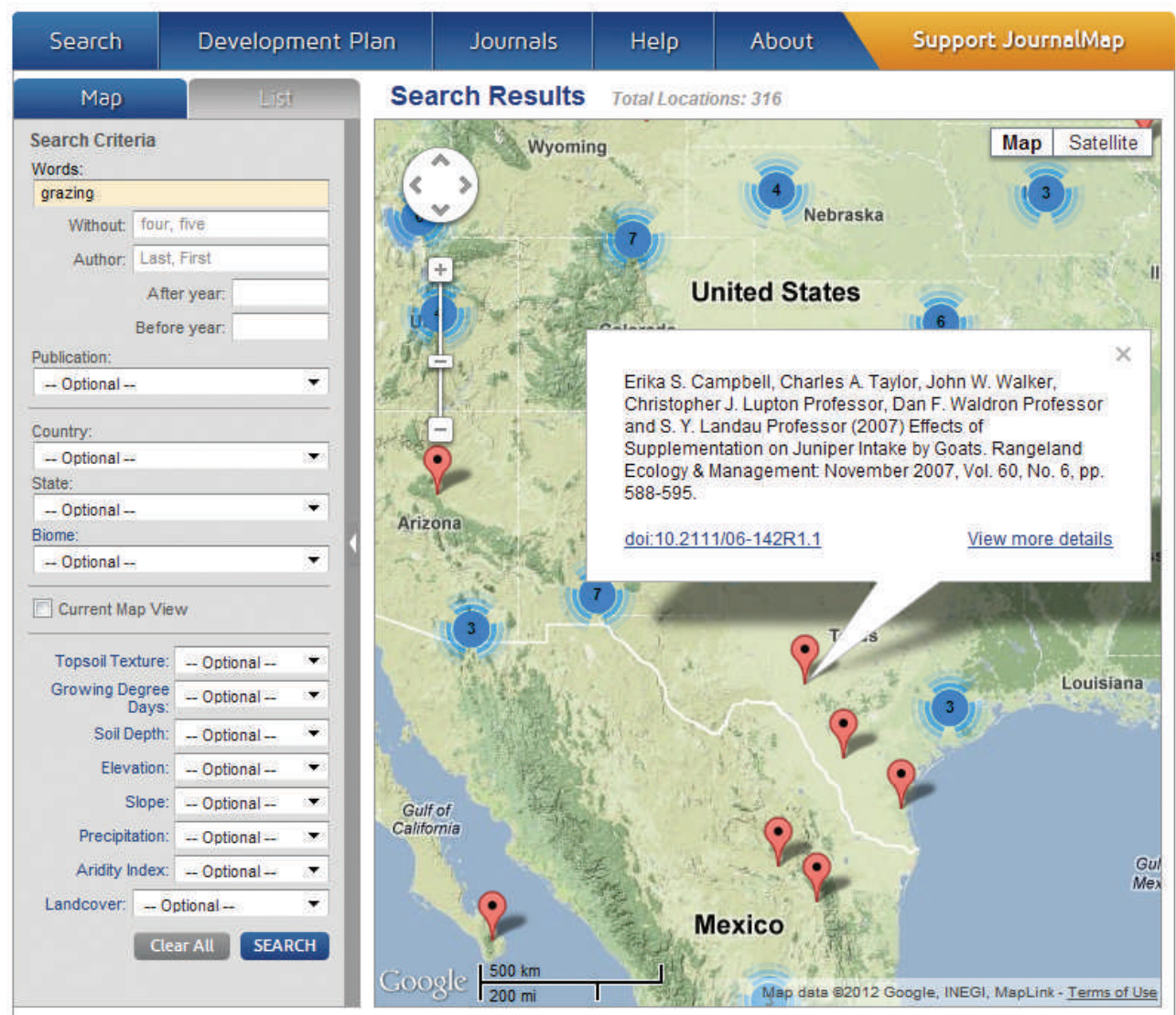

Figure 5. JournalMap is a geographic and topical search tool for finding relevant ecological literature. Locations of field studies were determined from coordinates reported in published articles. With JournalMap it is possible not only to identify what research has been done for a specific area and topic but also to search for literature from similar ecological areas based on soil, climate, and vegetation attributes.

and inappropriate use of data while allowing greater public access to large data sets like the National Resources Inventory (NRI) or agency management data.

\section{Improving Impact and Reach of Rangeland Research} Web 2.0 tools also have the ability to improve the exposure and use of rangeland research. Social networking services like Facebook, Twitter, and Pinterest and automatic rich site summary (RSS) feeds make communicating about new research and tools to diverse audiences much easier and faster than traditional routes like hard-copy publications, scientific publications, or word of mouth. Additionally, sites like eXtension $^{\mathrm{ix}}$ and Rangelands West ${ }^{\mathrm{x}}$ collate, interpret, and publicize rangeland-related information from many difference sources to targeted audiences. ${ }^{8}$

Also, with Web 2.0 technologies it is possible to monitor the use and rebroadcasting of information. This has led to the

\footnotetext{
ix The eXtension Web site can be accessed at http://www.extension.org.

${ }^{x}$ The Rangelands West Web site can be accessed at http://www. rangelandswest.org.
}

development of alternative ways of measuring impact of research (i.e., "altmetrics") based off attributes like number of times read, rebroadcast, or downloaded. ${ }^{9}$ Combined with more traditional measures of research impact (e.g., citation counts), altmetrics open new opportunities to gauge impact and reach of rangeland research and tools, especially for information published outside scientific journals (e.g., agency reports).

\section{Potential Problems and Barriers}

While there is great potential for Web 2.0 tools to contribute to rangeland management, there are several significant barriers to their widespread adoption. In some cases these barriers are unique to Web 2.0 tools, but for the most part they are existing problems that become magnified as the amounts of and access to data dramatically increases. A set of significant issues that must be addressed to move forward is presented below.

The Internet is infamous for information "recycling" where the same material shows up in many locations-either without sources or wrongly referenced. While information recycling happens often with rules of thumb or conventional wisdom, it can also happen with actual data when, for in- 


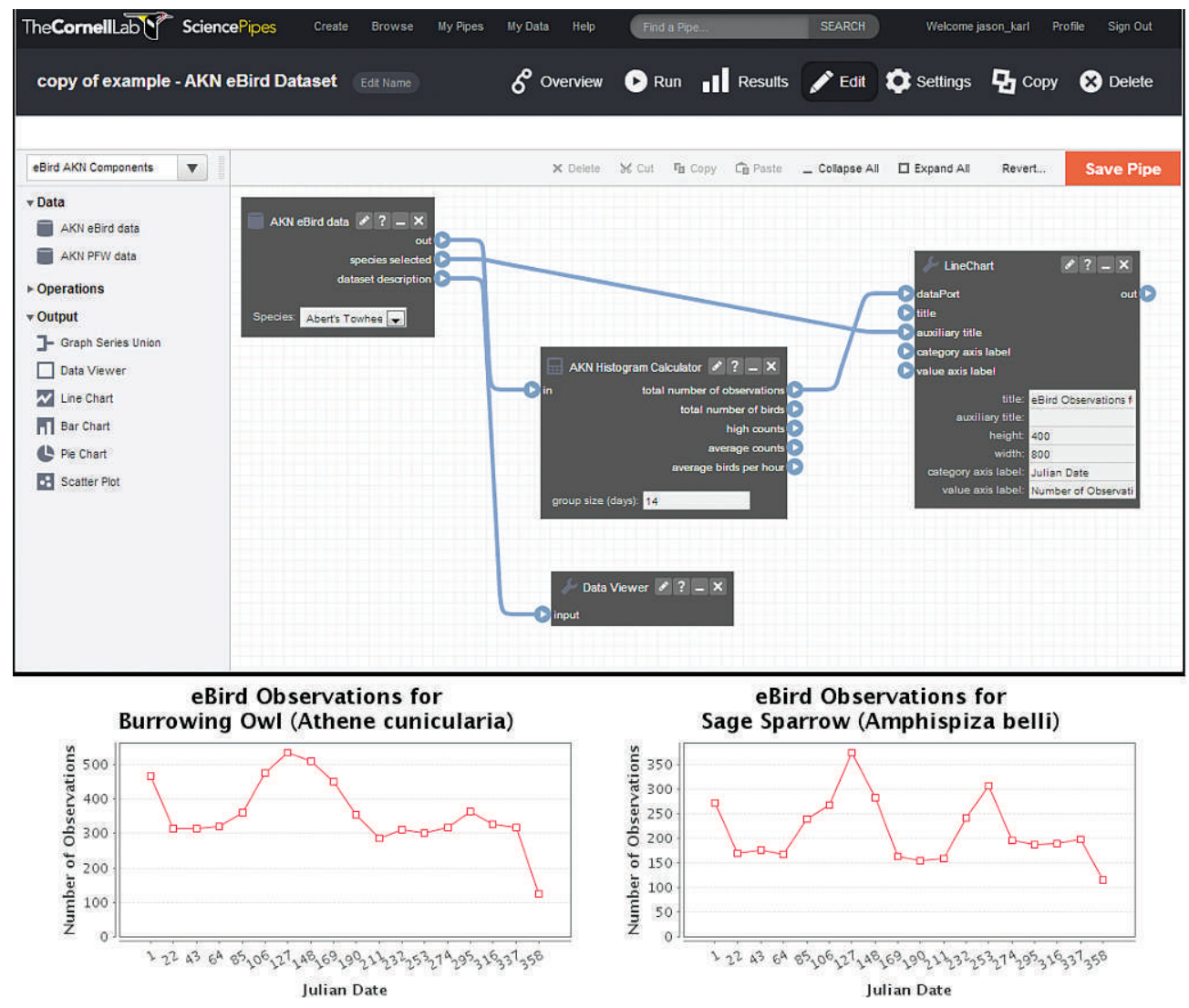

Figure 6. Users of the SciencePipes Web site (http://sciencepipes.org) can use a graphic interface to find, query, and relate biodiversity databases. The results of these queries can be output to graphs or tables that can be downloaded or embedded into other Web sites

stance, two databases use the same source for part of their collection. In this case only part of the data set is recycled, but it is often difficult to determine which information it is. The solution for information recycling is thorough and rigorous attribution of the sources of data. Social networking sites are famous for redistributing data in the form of "likes," "retweets," and "repins." Somewhat ironically though, the emphasis in Web 2.0 tools on redistributing information may help alleviate some of the problems with information recycling because the original source is attributed.

Perhaps a larger issue relative to data use, however, is adequate documentation of its purpose, history, and meaning through metadata. ${ }^{10}$ Metadata standards for geographic data (e.g., Federal Geographic Data Committee Metadata Standard $)^{\text {xi }}$ have been widely adopted, but similar standards (e.g., Ecological Metadata Language) ${ }^{11, x i i}$ for ecological data have not seen widespread adoption within the rangeland profession. Nobody will argue that data documentation is unnecessary, but metadata are often an afterthought and poorly attributed. Transparency of data sources and adequate docu-

\footnotetext{
xiThe FGDC Metadata Standard can be accessed at http://www.fgdc. gov/metadata.

xiiThe Ecological Metadata Language standard can be accessed at http:// knb.ecoinformatics.org/software/eml/.
}

mentation through metadata are paramount to building and maintaining trust in the quality of online information and knowledge systems.

Bias and quality are primary data concerns for rangeland ecology and management, and the idea of opening up the process of information collection, interpretation, and use to a broad audience (that includes the public) heightens these concerns. The dynamic creation and editing of data and information promoted by Web 2.0 technologies also challenge the traditional notion of peer review. ${ }^{4}$ Intentional bias (e.g., modifying a wiki entry with false information or to promote an agenda, or submitting false data to a database) is certainly problematic for information systems that are open to editing by large groups, but measures can be put into place to minimize its occurrence and impact (e.g., accepting submissions or edits only from registered users like in the Methods Guide or screening submissions or edits prior to accepting them like in the USA Phenology Network). ${ }^{7}$ More problematic, however, is unintentional bias that comes from uneven data collection or misinterpretation of data. These problems are not new, however, and have been well documented in data sets like plant and animal occurrences. ${ }^{12}$ The process of collating existing data sets and making them widely available should help in the identification of such unintentional bias and offer the opportunity to minimize its impact. Issues of data quality 
and bias, however, argue strongly for 1) providing adequate documentation of data origin and analysis and 2) making available raw data as well as syntheses and interpretations.

The inability or unwillingness to share information or collaborate is a threat to long-term success in rangeland management. The reasons for not sharing data or collaborating are varied, but the increasing rates of change that rangelands are experiencing will require synthesis of as much information as is possible because the information necessary to address novel disturbance regimes is often very limited. The ability to conduct ecological synthesis studies requires open sharing of not only hypotheses, methods, and summary results (i.e., what is presented in published studies) but also raw data and processing information. ${ }^{13}$ In many cases, lack of sharing is simply the result of failure to consider it as a priority. For example, the National Soil Information System (NASIS) ${ }^{x i i i}$ contains data on soils and vegetation from many plots that were used to create ecological site descriptions. These data could be useful in interpreting ecological site descriptions or in other projects, but only summaries of the data are publically available through the ecological site descriptions. In other cases, there are concerns about misuse of the data. We recognize legitimate concerns over access to private or proprietary data, but we encourage managers and land owners to explore creative ways to make information available while protecting privacy. Web 2.0 tools can provide not only the means for making data widely available, but also, as illustrated by SciencePipes, platforms for their appropriate use.

Many online databases and tools designed to assist land managers and ecologists suffer from poor interoperability with similar sites and, as a result, a dilution of effort. In other words, many sites are doing the same thing but not sharing information so that any one site does not contain enough information to be complete or useful. For example, there are multiple databases that track and map the occurrences of invasive species in Oregon (e.g., WeedMapper, ${ }^{\text {xiv }}$ Oregon State University; Invaders database, ${ }^{\text {,v }}$ University of Montana-Missoula; and Oregon Invasive Species Hotline, ${ }^{\text {xi }}$ Oregon Public Broadcasting). These sites represent isolated efforts and present different data. Of these, WeedMapper is the most comprehensive, but the ability to share information between the sites (e.g., new submissions to one site would be reflected in the other sites) would advance the mission of all three programs.A lack of consistency with how data are collected and reported also discourages interoperability. Data collected using the same methods can, in many cases, be combined. But if different methods were used, then it may be possible to combine only summaries of the data. In some cases even data summaries may not be compatible due to differences in defi-

\footnotetext{
xiii The NASIS Web site can be accessed at http://soils.usda.gov/technical/ nasis/.

xiv The WeedMapper Web site can be accessed at http://weedmapper.org.

${ }^{x v}$ The Invaders database can be accessed at http://invader.dbs.umt.edu.

xvi The Oregon Invasive Species Hotline Web site can be accessed at http://oregoninvasiveshotline.org.
}

nition of basic concepts. For example, cover estimates from foliar cover and total canopy cover methods cannot be combined because they measure different things. ${ }^{14}$ While we recognize that project needs should dictate the methods used for field studies and monitoring, the use of standard and widely applied methods should be encouraged whenever possible.

Obscurity is another impediment to widespread adoption of Internet technologies for a new information and management system. The diversity of communication means used by rangeland professionals makes it difficult to get the word out about new applications or databases. Additionally, many potentially useful tools have been developed by other ecology or land management disciplines but are relatively unknown in rangeland disciplines. An example of this is VegBank, xvii an online database of vegetation plot data that is open for anyone to contribute to. VegBank data are routinely used for developing broad-scale land cover classifications and to support ecological research, but there is potential for this tool (or something similar) to support more local management applications. As of 4 January 2013, VegBank has data from 72,907 plots. Of these, however, the only contributors of rangeland plots have been regional mapping efforts like Southwest GAP. Obscurity can be addressed only through aggressive communication of new tools and databases both within and between disciplines.

\section{Conclusion: Moving Forward}

Fifteen to 20 years ago, our ability to find, generate, and access high-quality information was much more limited than it is today. Most projects started off with digitizing basic layers like roads, ownership, and administrative units from hardcopy maps before any analysis ever occurred. GPS units were expensive, large, and finicky. Satellite imagery was expensive and greatly taxed computer systems. Literature searches were time consuming and involved prolonged periods spent at the library. We now have near-instant (and in many cases free) access to reams of high-quality data and can focus on developing data sets central to our questions and synthesizing existing data sets to answer novel questions. Taking advantage of this explosion of information, however, will require a change in focus from discrete and isolated projects to comprehensive knowledge systems that can be tapped (and supplemented as necessary) to respond to new management issues as they arise.

Rangeland ecology and management has always been a synthetic discipline-drawing from diverse fields like animal and plant biology, and soil science. This integration has led to theoretical developments (e.g., ecological site concepts) ${ }^{15}$ and practical tools (e.g., rangeland health indicators) ${ }^{16}$ that would not have been possible otherwise. A contribution that our field could make is to demonstrate integration of disparate services and information sources to produce applied

\footnotetext{
xvii VegBank can be accessed at http://vegbank.org.
} 
systems of knowledge. A wider adoption of emerging information technologies that emphasize collaboration, data sharing, and maximal use of existing information would facilitate this. While rangeland science to date has not produced many of the applications that are driving the evolution of science knowledge, we can take advantage of them. If we do not, we risk being left behind or having contributions of rangeland ecology marginalized within the wider scientific and natural resource management community.

The Research Information Network ${ }^{4}$ study of Web 2.0 technology adoption concluded that "widespread adoption of Web 2.0 services by researchers depends on their being intuitive and easy to use, and incremental in building on existing practices." The ideas presented above represent incremental steps to improving our current ways of collecting, using, and disseminating information. This approach moves us toward the kinds of knowledge systems we need to address the rangeland management problems of today and tomorrow.

\section{REFERENCES}

1. Peters, D., J. Belnap, J. Ludwig, S. L. Collins, J. Paruelo, M. T. Hoffman, and K. M. Havstad. 2012. How to be general, yet specific: the conundrum of rangeland science in the 21st century. Rangeland Ecology \& Management 65:613-622.

2. Tapscott, D., and A. D. Williams. 2006. Wikinomics: how mass collaboration changes everything. New York, NY, USA: Pengiun Group. 351 p.

3. Shelly, G. B., and M. Frydenberg. 2010. Web 2.0: concepts and applications. Boston, MA, USA: Course Technology, Cengage Learning. 288 p.

4. Research Information Network. 2010. If you built it, will they come? How researchers perceive and use Web 2.0. London, UK: Research Information Network. 64 p.

5. Beaudette, D. E., And A. T. O’Geen. 2010. An iPhone application for on-demand access to digital soil survey information. Soil Science Society of America Journal 74:1682-1684.

6. Karl, J. W., K. Colson, And H. Swartz. 2011. Rangeland Assessment and Monitoring Methods Guide: an interactive tool for selecting methods for assessment and monitoring. Rangelands 33(4):48-54.
7. Betancourt, J. L., M. D. Schwartz, D. D. Breshears, D. R. Cayan, M. D. Dettinger, D. W. Inouye, E. Post, and B. C. Reed. 2005. Implementing a USA-National Phenology Network (USA-NPN). EOS 86:539-542.

8. Hutchinson, B., J. Pfander, J. Tanaka, and J. Clark. 2011. Rangelands West/Global Rangelands, eXtension Rangelands, and the Range Science Information System: a suite of new web resources. Rangelands 33(4):55-63.

9. Priem, J., P. Groth, and D. Taraborelli. 2012. The altmetrics collection. PLOS ONE 7(11):e48753.

10. Michener, W. K. 2006. Meta-information concepts for ecological data management. Ecological Informatics 1:3-7.

11. Michener, W. K., J. W. Brunt, J. J. Helly, T. B. Kirchner, AND S. G. Stafford. 1997. Nongeospatial metadata for the ecological sciences. Ecological Applications 7:330-342.

12. Kadmon, R., O. Farber, and A. Danin. 2004. Effect of roadside bias on the accuracy of predictive maps produced by bioclimatic models. Ecological Applications 14:401-413.

13. Ellison, A. M. 2010. Repeatability and transparency in ecological research. Ecology 91:2536-2539.

14. Toevs, G. R., J. W. Karl, J. J. Taylor, C. S. Spurrier, M. S. Karl, M. R. Вobo, and J. E. Herrick. 2011. Consistent indicators and methods and a scalable sample design to meet assessment, inventory, and monitoring information needs across scales. Rangelands 33(4):14-20.

15. Brown, J. R. 2010. Ecological sites: their history, status, and future. Rangelands 32(6):5-8.

16. Pellant, M., P. Shaver, D. A. Pyke, and J. E. Herrick. 2005. Interpreting indicators of rangeland health, version 4. Denver, CO, USA: US Department of the Interior-Bureau of Land Management National Science and Technology Center. 122 p.

Authors are Research Ecologist, jkarl@nmsu.edu (Karl), and Soil Scientist (Herrick), USDA-ARS Jornada Experimental Range, Las Cruces, NM 88003, USA. Mention of a proprietary product does not constitute a guarantee or warranty of the product by USDA or the authors and does not imply its approval to the exclusion of other products that also may be suitable. 